BMJ Open

Diabetes

Research

\& Care

\title{
Experiences and perspectives of the parents of emerging adults living with type 1 diabetes
}

\author{
Cheryl Pritlove (D) , ${ }^{1,2}$ Benjamin Markowitz, ${ }^{1}$ Geetha Mukerji, ${ }^{3,4}$ Andrew Advani, ${ }^{5}$ \\ Janet A Parsons ${ }^{1,6}$
}

To cite: Pritlove C, Markowitz B, Mukerji G, et al. Experiences and perspectives of the parents of emerging adults living with type 1 diabetes. BMJ Open Diab Res Care 2020;8:e001125. doi:10.1136/ bmjdrc-2019-001125

- Additional material is published online only. To view, please visit the journal online (http://dx.doi.org/10.1136/ bmjdrc-2019-001125).

AA and JAP contributed equally.

Received 17 December 2019 Revised 11 August 2020 Accepted 13 August 2020
Check for updates

(c) Author(s) (or their employer(s)) 2020. Re-use permitted under CC BY-NC. No commercial re-use. See rights and permissions. Published by BMJ.

For numbered affiliations see end of article.

Correspondence to Dr Cheryl Pritlove; pritlovec@smh.ca

\section{ABSTRACT}

Introduction Whereas it is widely recognized that emerging adulthood can be a difficult time in the life of an individual living with type 1 diabetes, relatively little is known about the experiences of their parents or guardians. These individuals once shouldered much of the burden for their child's diabetes 'self'-management, yet their contribution is often overlooked by the adult healthcare system. Here, we set out to gain an understanding of the perspectives of parents of emerging adults living with type 1 diabetes.

Research design and methods Semi-structured interviews were performed with a purposeful sample of parents of emerging adults with type 1 diabetes recruited from two urban young adult diabetes clinics and through a national diabetes charity. Thematic coding was derived using a constant comparative approach.

Results Analysis of interviews with 16 parents of emerging adults with type 1 diabetes identified three themes: parental experiences of the transition to adult care; negotiating parent-child roles, responsibilities and relationships; and new and evolving fears. Parents spoke in detail about the time surrounding their child's diagnosis of type 1 diabetes to emphasize the complexity of diabetes care and the need to establish a 'new normal' for the family. In turn, adolescence and emerging adulthood required a renegotiation of roles and responsibilities, with many parents continuing to play a role in high-level diabetes management. Several parents of emerging adults with type 1 diabetes (particularly those of young men) vocalized worries about their child's readiness to assume responsibility for their self-care, and some expressed frustration with the apparent dichotomy in the role expectations of parents between the pediatric and adult care settings.

Conclusions Adult healthcare providers should recognize both the ongoing involvement of parents in the 'self'management of emerging adults with type 1 diabetes and the unique aspects of the caregiver burden that they experience.

\section{INTRODUCTION}

Throughout the life course, type 1 diabetes 'self'-management practices are influenced by interactions between persons with diabetes and others, including their peers, healthcare providers and family members. Parental involvement is especially important during

\section{Significance of this study}

What is already known about this subject?

- The importance of parental involvement in the daily care of children and youth with type 1 diabetes is widely appreciated, yet little is known about the parental experience and role once their child reaches emerging adulthood and care transitions take place.

What are the new findings?

- This study found that parents continue to play an active role in the diabetes management of their child well into the emerging adult years, requiring a renegotiation of responsibilities that often proved challenging for parents, provoking fear and worry, particularly when it was perceived that their child was not managing their diabetes well.

- Young men may be particularly vulnerable to poor diabetes self-management.

How might these results change the focus of research or clinical practice?

- Healthcare providers should be mindful of the roles that parents continue to play in the 'self'-management of emerging adults with type 1 diabetes and should be cognizant of the psychosocial stresses experienced by the caregiving parents of young adult patients during the transitioning years.

childhood, when parents shoulder the vast majority of the burden of diabetes responsibility. These interactions can shape the future habits of the person with diabetes, ${ }^{1-6}$ and they can have a profound effect on the psychosocial well-being of the parent. ${ }^{7}$ During early emerging adulthood (18-24 years), ${ }^{8}$ there is a continuing shift in diabetes responsibility away from the parent and toward the adult child. $^{9-11}$ A time of substantial emotional, psychological and social change, this period of life is often associated with loss to follow-up, the emergence of long-term complications and increased risk of adverse health outcomes. ${ }^{12}$ However, while the experiences of parents of children and adolescents with type 1 diabetes have been documented, ${ }^{13-17}$ 
there is a comparative dearth of information detailing the experiences of parents during the early emerging adult years.

During emerging adulthood, the parents of individuals with type 1 diabetes experience a dramatic shift in their caregiver role-from acting as the fulcrum of communication, diabetes knowledge and caretaking, to being left on the outskirts of care. ${ }^{8}$ This shift is compounded by a change in communication patterns between parents and healthcare practitioners. For instance, while parents may once have had an open discourse with their child's healthcare provider in a family-centric model of pediatric care delivery, in adult care, privacy restrictions limit information sharing between healthcare providers and parents. ${ }^{18-20}$ Such shifts are further complicated by a reported drop in clinic attendance and adherence to diabetes self-management recommendations during the emerging adult years. ${ }^{21}$ Despite these challenges, parents often continue to play an active, although evolving, role in their adult child's daily diabetes care. ${ }^{20}$ In this article, we set out to explore the experiences, perspectives, and needs of parents of emerging adults living with type 1 diabetes during the transition phase. Our goal was to understand the challenges they confront and to help identify support needs and appropriate care resources for emerging adults and their parents.

\section{METHODS}

\section{Sampling and recruitment}

Parents of emerging adults living with type 1 diabetes were recruited using a purposive sampling approach. ${ }^{22}$ To capture a breadth of experiences, we employed broad inclusion criteria. ${ }^{23}$ Parents were eligible to participate in the study if they spoke English and had a child living with type 1 diabetes and aged 18-24 years. Parents across Canada were notified about the study through Diabetes Canada as well as through the circle of care at young adult diabetes clinics in two tertiary care hospitals in Toronto, Canada. All participants provided verbal (for telephone interviews) or written (for inperson interviews) informed consent. To protect the anonymity and confidentiality of participants, alphanumeric codes were assigned.

\section{Data collection}

All interviews were conducted by the first author (CP) in a private room at St Michael's Hospital. Semistructured interviews were designed to generate indepth understanding of parents' experiences of caregiving for a child living with type 1 diabetes, the changes and challenges they experienced during their child's transition to adulthood and adult healthcare services, their current involvement in diabetes management, and their experiences with and need for support (see online supplemental file for interview questions). The interview guide was designed by a trained qualitative researcher and informed by the extant literature in the area. Participants were encouraged at the onset of the interview to take the conversation in a direction that they believed to be most relevant to their experiences. They were also provided with an opportunity at the end of the interview to discuss any topics that they felt were important, but not adequately addressed throughout the conversation. In addition to the interview, participants were asked to complete a demographic questionnaire.

\section{Analysis}

Interviews lasted between 40 and $110 \mathrm{~min}$, were transcribed verbatim and checked for accuracy. Interview transcripts were analyzed in an iterative fashion concurrent with data collection. Transcripts were coded line by line to construct emergent codes, categories, and themes and to derive analytic thoughts. Memos were generated following each reading of the transcripts. Two researchers (CP and $\mathrm{BM}$ ) independently coded the data and held meetings to develop, refine and reach consensus on key codes and themes. ${ }^{24}$ A codebook was developed iteratively through this process. ${ }^{25}$ NVivo V.11 data analysis software was used to support a second round of data analysis, using the codebook, and for producing thematic reports of interview quotations. Preliminary themes were identified as those that related directly to the project objectives, occurred consistently throughout individual interviews, and were discussed by several of the participants. Following this process of thematic coding, a constant comparative approach was applied to thoroughly assess and better understand influences that contributed to differences and similarities between participants' accounts. ${ }^{26}$ Tracy's eight 'big-tent' criteria ${ }^{27}$ for assuring quality in qualitative research were applied throughout the study, including worthy topic; rich rigor (eg, analytic notes and memos, identification of negative or outlier cases); reflexivity (eg, acknowledgment of and engagement with our epistemological, ontological, and theoretical assumptions as well as our personal, social, and institutional influences during analysis); and credibility (eg, thick description).

\section{RESULTS}

Sixteen parents of emerging adults with type 1 diabetes took part in the study. It was suspected after interview 13 that we had reached thematic saturation ${ }^{28-30}$; the remaining three interviews confirmed this, with no new patterns, themes, or perspectives emerging from the data. Of the 16 participants, 13 were women and 3 were men. Their children ranged in age from 18 to 23 years and had been living with type 1 diabetes for an average of 12 years (range $4-20$ years). All of the participants described children who transitioned out of pediatric care at age 18 , with all but one being transferred to emerging adult diabetes transition clinics. The one emerging adult who transitioned to adult care was later referred to a transition clinic. Of the 16 participants, 10 parents perceived their child was managing their illness well during the transition phase, while 6 felt their 
Table 1 Demographic characteristics of study participants

Frequency, $\mathbf{n}(\%)$ (unless stated otherwise)

\section{Characteristics}

$53(45-59)$

Age of participants at time of interview, mean (range), years

Age of child at time of interview, mean $20(18-23)$ (range), years

\begin{tabular}{|c|c|}
\hline \multicolumn{2}{|l|}{ Gender of parent } \\
\hline Female & $13(81)$ \\
\hline Male & $3(19)$ \\
\hline \multicolumn{2}{|l|}{ Gender of child } \\
\hline Female & $6(38)$ \\
\hline Male & $10(62)$ \\
\hline \multicolumn{2}{|l|}{ Marital status } \\
\hline Spouse or partner & $13(81)$ \\
\hline Single/divorced & $2(13)$ \\
\hline Widowed & $1(6)$ \\
\hline \multicolumn{2}{|l|}{ Education } \\
\hline High school & $4(25)$ \\
\hline Postsecondary degree(s) & $12(75)$ \\
\hline \multicolumn{2}{|l|}{ Employment status } \\
\hline Full time & $9(56)$ \\
\hline Part-time & $1(6)$ \\
\hline Self-employed & $2(13)$ \\
\hline Full-time home maker & $4(25)$ \\
\hline \multicolumn{2}{|l|}{ Total household income } \\
\hline$\$ 40000-\$ 60000$ & $2(12.5)$ \\
\hline$\$ 60000-\$ 80000$ & $1(6)$ \\
\hline$>\$ 100000$ & $11(69)$ \\
\hline Unknown & $2(12.5)$ \\
\hline \multicolumn{2}{|l|}{ Private health insurance } \\
\hline Yes & $13(81)$ \\
\hline No & $3(19)$ \\
\hline \multicolumn{2}{|l|}{ Born in Canada } \\
\hline Yes & $10(63)$ \\
\hline No & $6(37)$ \\
\hline
\end{tabular}

children ( $\mathrm{n}=5$ men; $\mathrm{n}=1$ women) were managing their illness poorly. Most parents were in the $>\$ 100000$ socioeconomic bracket and were partnered at the time of the interview. The majority were also working full time and had access to private health insurance. Demographic information of the study participants is provided in table 1.

The results from this study identified three key themes: (1) parental experiences of transition; (2) renegotiating parent-child roles, responsibilities and relationships; and (3) new and evolving fears.

\section{Parental experiences of transition}

The parents spoke in depth about the moments surrounding their child's diagnosis of type 1 diabetes. They stressed that recounting these experiences was not only important for providing a comparative landscape through which to understand their current experiences as parents of emerging adults living with type 1 diabetes, but that these accounts also provided necessary context to understand the trajectory and complexity of diabetes and its management from a caregiver perspective.

Parents described the sudden onslaught of responsibility and profound emotional distress that accompanied their child's diagnosis. Learning to traverse the complex, unpredictable terrain of diabetes was challenging and described by many as 'life-changing'. Parents emphasized the intricate and highly specialized nature of diabetes care and stressed the time and dedication needed to accrue appropriate expertise. Throughout childhood and adolescence, parents were involved in every aspect of daily management. Parents emphasized the allconsuming nature of this work and highlighted the many years of ongoing education, practical hands-on experience, and collaboration with their child's healthcare team to acquire and refine their expertise. While this was exhausting work, parents were driven by messaging from their child's healthcare team regarding parental responsibility and accountability for good diabetes management. As one parent recalls:

P5: When they are diagnosed, we're told as we leave the hospital that as long as we do everything that we are taught to do for them they will be healthy and stay alive, but that if we don't do everything we're told to do, then [our child] could die. That's one of the last statements they tell you when you leave the hospital.

Over time and with support, parents described settling into a 'new normal', characterized by daily diabetes management. With greater control and confidence in their ability to manage their child's diabetes came a sense of comfort that their child could indeed live a healthy, long and 'normal' life with type 1 diabetes. As their child reached the age of majority, however, this 'new normal' was disrupted. Indeed, parents described significant shifts in their role from the responsible and accountable healthcare provider, diabetes manager and decision maker, to a more supportive and advisory role. Many emphasized the initial struggle to 'let go', as they relinquished control over their child's diabetes management. Earlier messaging around the complexity of diabetes, the need for vigilance and the consequences of poor control, as well as the necessity of strong parental involvement, partially informed this struggle. Many parents expressed feelings of ambiguity and uncertainty regarding their place in this new care arrangement. A participant commented:

P3: I kind of had a period of 'what now'? You know, like

I mean it was never my disease to deal with [but] now what's my role? And figuring out you know, where I fit. 
And that's just kind of taken a little bit of internal work I guess to kind of re-find your place.

The parents in this study described lives that revolved around diabetes and its management, often for over a decade. As their children entered adulthood, parents struggled with their own transitions-as roles, responsibilities and relationships were renegotiated and redefined.

\section{Renegotiating parent-child roles, responsibilities and relationships}

When children were first diagnosed, parents described a disruption in the established parent-child relationship, where parents felt they needed to constantly supervise and control their child's actions. Part of letting go during the emerging adult years meant that they had to once again redefine their relationship. Although many parents found this challenging, they wanted to encourage independence and some even looked forward to new possibilities for freedom that this would bring in their own lives. Parents worked with their children to agree on a level of involvement that would support independence while also ensuring that necessary supports were in place. Open communication, ongoing negotiations, flexibility and mutual agreement of new roles and responsibilities were essential to this transition process. As one parent explains:

P7: Find something that's sort of a happy medium, that you can be satisfied with but so can your child and agree to that, agree that this is what you're going to do...just because technically they're an adult doesn't mean you can wipe your hands of them and say 'okay, you're on your own now'. They're still young... and they still need that encouragement, support and guidance.

Understanding first-hand the level of expertise and support required for diabetes management, parents often stressed the importance of a ramped approach, where responsibility for care shifted gradually from parent to emerging adult, permitting their child the necessary time to develop and refine their management skills. Parents sometimes found themselves teetering between a desire to foster greater independence while also acknowledging legitimate health-related concerns. As one parent explains, "You want to give them enough rope so that they can learn things for themselves, but not enough to hang themselves with" (P6).

Most parents described involvement in 'higher-level' diabetes management activities (eg, providing backup support, guidance and education) and assistance with non-daily tasks, such as ordering (and paying for) supplies, making medical appointments and providing transportation to clinics. Parents recognized the demands of daily diabetes management and the risk of burn-out and offered these supports to ensure a safe transition. As one parent commented:

P15: I have been doing all of the medical claims and everything. So, she has done zero of that yet. That is something that we didn't want her to worry about, now that she has to do all the [daily diabetes management] on her own.

The level of parental involvement ultimately varied according to their perceptions of their child's capacity and readiness to manage diabetes on their own. Whereas all the participants valued their child's independence, they also emphasized balancing this with other considerations, including their child's individual life circumstances (eg, living at home/living away from home), skill level and maturity. Besides age, parents stressed other determinants that influence capacity to self-manage that are important to consider when negotiating roles and responsibilities. For instance, some parents felt that gender intersected with age in a way that differently prepared young women and men to take on independent self-management. A parent commented:

P16: [My daughter] is so dedicated to testing; she tests probably 8, 9 times a day. She is the complete opposite of [my son], complete opposite and she hasn't been in the hospital nearly as many times as [my son], you know, but boys and girls are so different. I think girls just mature much earlier and you need that maturity to take on diabetes [self-management]. So, I find myself more involved in his care, even though he's the older of the two.

\section{New and evolving fears}

Recent shifts in control over diabetes management meant that parents were often 'left in the dark' and reliant on the willingness of their child to disclose health-related information. Coming to terms with this loss of control was difficult for some parents:

P3: I think now the biggest [fear] is that, all through the years you have some sort of control... and now I can't tell you what his last A1C was. That's all information that he keeps to himself...That was a big shift, to kind of relinquish control when I had so much control.

Relinquishing control was particularly difficult when it was perceived by parents that their child was not managing well. Indeed, parental perceptions about their child's maturity, readiness and management competency informed the extent of their worry:

P13: [Diabetes is] a $24 / 7$ job. It's so much stress and pressure and it really takes time to adjust to that level of responsibility. Some young people can handle it, but he's just not ready to take that on by himself and that's come through with some of his actions and recent episodes [of diabetic ketoacidosis (DKA)]. And it's just gut wrenching for us as parents to sit by and watch.

Acknowledgment of this complexity was seen as crucial to fostering independent and safe self-management, providing the right amount of responsibility, at the right time, for the right individual. However, some parents worried that this was not always well understood from a healthcare system perspective that tends to adopt more of a one-size-fits-all approach. Struggling to reconcile 
what she saw as a tension in messaging between pediatric and adult healthcare settings, one parent argues that the abrupt change to the care dynamic is not only challenging for parents, but can also impose unrealistic expectations on emerging adults to take on too much, too soon:

\begin{abstract}
P5: They said 'it's ridiculous that you feel you need to come into your kid's room, they are 18, it's ridiculous, you have to give them control, you can't coddle them, you can't baby them'...And I said, 'you know, it boggles my mind that for 14 years I am told by the healthcare system that it's my responsibility to keep my kid alive, it's my responsibility by law to make sure that they are safe, it's my responsibility to make sure they do everything they are supposed to do and yet, you think that at the age of 18 , all of a sudden, they are supposed to know all that and I am out?' I think that's ridiculous.
\end{abstract}

Some parents expressed particular concerns about their sons, explaining that medical messages of independent illness management paired with broader social constructions of masculinity (eg, 'self-reliant', 'tough', 'in control') further discouraged young men from acknowledging the need for support and help-seeking in order to preserve masculinized identities. These messages were seen as being particularly out of line with parental perceptions of young men as being less mature and less ready to assume this level of responsibility as compared with young women living with type 1 diabetes. In a broader discussion of gender, age and maturity, one parent explains:

P7: Especially with a boy, when they turn 18, it's like, well 'I'm a man now and I'm responsible for my decisions and this is my life, and it's not yours and now I can decide' and that's fine and well and we're happy that he's taking sort of that independent lead, but he's just not mature enough to make the proper decisions at this stage, I feel.

Parents stressed the individualized nature of this illness, and while acknowledging issues of confidentiality and the importance of private consultations between their adult child and care providers, some felt that in the interest of enhancing more person-centered approaches to the delivery of care, there could be more opportunities for collaboration between parents, patients and providers. Parents argued that this is particularly important during the early stages of transition, when patient-provider relations are being established:

P5: It's not like we need to take control and keep control of our children's lives, it's that we want whoever is going to start taking over it and helping them with it to understand that individual child's requirements, because every type 1 [sic] is different. And who knows better than the parent? Telling [the patient] that you need to do this because this is what the book says you need to do, well it may not work for that type 1 [sic]. If you spend time talking to the parents, well, they can actually say 'well, this has been our experience'.

Being able to dialogue with their child's new healthcare team was described as 'comforting' by those parents who were given the opportunity. As one parent explains, meeting with the healthcare team can promote more trusting relationships between parents and providers in a way that helps to manage parental fear and fosters improved well-being:

P7: Well, we did have an opportunity to meet with the [healthcare] staff that he would be dealing with and they quite honestly were absolutely wonderful. I walked away feeling pretty good that [son's name] had some pretty knowledgeable people there that would be able to help him out.

In addition to collaborating with healthcare providers to facilitate their child's transition, parents also expressed a need for transition supports of their own. When their children graduated from pediatric care, parents not only lost access to important professional advice and guidance, they also lost a key source of support. Some parents felt that the healthcare system would be an appropriate space to deliver parental transition supports:

P3: I think [there is a need for] a parent transition... when you're just kind of left out in that [waiting] room when they're having their own appointments, to be able to have someone work with you on how to deal with your new role and the feelings that you're experiencing.

Although not all parents described a need for transition supports, many did, emphasizing the importance of developing services that recognize the continuing role that parents play and the new and changing challenges and fears that they confront in this role. It was argued that the delivery of such supports would not only improve their own well-being, but would also help them to better support their child during this life stage.

\section{DISCUSSION}

Despite their continued involvement in their adult child's diabetes 'self'-management, there is little opportunity provided within the healthcare system for eliciting and addressing the concerns of the parents of emerging adults living with type 1 diabetes. In this article, we present the experiences of 16 parents of emerging adults with type 1 diabetes. For these parents, emerging adulthood disrupted what had become the 'new normal' that they worked hard to establish on diagnosis; roles had to be renegotiated; worries evolved; control had to be relinquished; and the apparently contradictory expectations of pediatric and adult healthcare providers could be frustrating. When structuring transition services or when providing individualized care to emerging adults living with chronic diseases, including type 1 diabetes, healthcare practitioners should be cognizant of the backdrop of evolving family relationships and the effect that transitions have both on the individual and their caregivers.

As their child progressed through emerging adulthood, parents described significant shifts in their role from the responsible and accountable healthcare provider, manager and decision maker, to a more supportive and 
advisory role. Relinquishing control could be difficult, requiring parents to both recognize and change deeply entrenched and habitual patterns of behavior, a struggle that has been highlighted in previous research with parents of emerging adults living with type 1 diabetes or other long-term health conditions. ${ }^{731} 32$ In this study, the extent of parental concern and willingness to relinquish control varied according to their perceptions about their child's psychological readiness, self-management skill, self-efficacy and overall perceived level of maturity. Thus, while emerging adulthood is often regarded as a time in which individuals establish independence, ${ }^{33}$ the findings from this study suggest that this process does not adhere to a one-size-fits-all framework. Indeed, parental accounts of the complexity, nuance and individualization of diabetes, as well as the complex and intersecting physical, psychological and social changes that occur during this life stage, signal the need for diverse and personcentered approaches to the delivery of care during the transition process.

Most healthcare systems are not equipped to draw a distinction between the developmental differences of individual adults after the legal age of majority, expecting a level of independence and autonomy that is (sometimes) incongruent with developmental maturity during emerging adulthood. However, this study, along with others, ${ }^{21} 31$ reinforces that emerging adults continue to receive varying degrees of parental support throughout the early emerging adult years. The tension between expectation and capacity can put emerging adults at risk for poor management and adverse health consequences, ${ }^{1034}$ and it is at the nexus of this tension that parents often intervene with the provision of support (eg, guidance and education, management of medical appointments, procurement of medical supplies, and completing insurance and accommodation forms). Indeed, while the parents in this study recognized the importance of and supported their child's progression toward independence, they also argued that young adults with lower diabetes-related selfefficacy may need additional support from parents as they acquire the needed expertise for independent selfmanagement. For instance, several parents commented on the role of gender in framing self-management readiness-unanimously agreeing that prototypical and socially enforced expectations of masculinity, which position men as being those who are 'self-reliant', 'tough', and 'in control', along with medical messages of independent illness management, placed restrictions on the opportunities for young men to express struggles with self-management and ask for help when it was needed. This finding confirms a wealth of research pertaining to men's health management and health-seeking practices more generally, which shows that masculine traits such as independence, stoicism, and toughness can negatively impact men's illness management and healthseeking behaviors. ${ }^{35}$ The finding also extends much of the, although limited, scholarship on gender and type 1 diabetes, which tends to situate young women as being particularly vulnerable to higher levels of diabetesrelated distress and poor medical management. ${ }^{13637}$ If young men are, as the parents in this study suggested, reluctant to voice their struggles with self-management in an effort to maintain socially constructed masculine ideals,${ }^{35}$ existing research may be under-representing the extent and source of young men's management struggles and need for support.

In unpacking parental experiences of transition, this study illuminates the difficulty of breaking habitual care practices and the steep learning curve involved in defining and adapting to new roles and responsibilities. Indeed, some parents likened this transition as being analogous to diagnosis, imbued with feelings of ambiguity and concern. However, unlike their earlier experiences, parents felt significantly less supported as their child transitioned into emerging adulthood, leaving them to navigate this unfamiliar terrain alone. Doing so often fostered a sense of uncertainty among parents regarding what constitutes an appropriate level of involvement, as well as concern about the health consequences of not being involved enough. Evidence shows that parental support and encouragement can help to promote improved self-efficacy and expertise among emerging adults in their self-management practices ${ }^{73}$ and thus parental involvement in care should not necessarily be discouraged. However, because parental involvement can also lead to reduced autonomy in early adulthood, ${ }^{33}$ parents may require ongoing support from healthcare providers as they determine how to best traverse the line of engagement in their adult child's health appropriately and with sensitivity.

Healthcare providers should be cognizant that, with shifting family dynamics, transition to adult diabetes care is not a single event, rather it represents one episode in a much longer and more gradual handover of responsibility. A number of practical steps can be introduced to help smooth the transition process for parents of emerging adults living with type 1 diabetes. First, prior to the transition to adult care, it may be helpful for parents to meet both the pediatric and adult diabetes care teams in a group setting with other parents of emerging adults with type 1 diabetes, to discuss common concerns about the transition process. Second, with the permission of their emerging adult, parents can be invited to attend their child's first appointment with their adult diabetes care team (and subsequent appointments if their child prefers). Third, parents may wish to meet with members of the multidisciplinary care team during their child's clinic visit to receive transition supports of their own. These appointments could be structured according to topics and strategies that parents identified as being most helpful, including how to negotiate new roles and responsibilities; locating and using practical, informational, psychosocial and human support; and identifying adaptive coping skills.

Our study has limitations. First, although we spoke with both men and women, the majority of our participants 
were mothers. This is perhaps reflective of broader trends in social reproduction, including divisions of domestic labor, where women continue to assume the bulk of caregiving work. ${ }^{38}$ While there were no notable gender differences among the parents in our study, it should be noted that our investigation was intended to better understand the parental experience from a broad range of perspectives, and was not designed to probe specifically for the impact of gender or other social determinants of health $(\mathrm{SDOH})$ on the parental experience of transition. Future studies may want to explore the impact of gender and other $\mathrm{SDOH}$, such as parental income, on experiences of type 1 diabetes transition during emerging adulthood. Second, because parents in this study were not privy to medical information pertaining to their child's type 1 diabetes (eg, hemoglobin $\mathrm{Alc}\left(\mathrm{HbA}_{1 \mathrm{c}}\right)$ values) and relied entirely on their child's disclosure of this information, few parents were able to share such details, commenting instead on their overall perception of their child's diabetes management. In turn, we are unable to comment on the relationship between perceptions of control and objective measures of diabetes control, such as $\mathrm{HbA}_{1 \mathrm{c}}$ or time in range.

In summary, the perspectives and experiences of the parents in this study highlight the complex, relational and nuanced nature of diabetes self-management that took years to master. The abrupt transfer of responsibility that coincides with the handover of care from the pediatric to the adult healthcare setting was problematized as potentially detrimental to a young adult's physical and psychosocial well-being. A progressive ramp-up in responsibility allowed time for children to transition into their new, more active roles, while also allowing parents to comfortably transition out of theirs. Healthcare providers should be mindful of the more gradual transitions that take place within families during emerging adulthood, as well as the impact that these transitions have on both the person with diabetes and their caregivers.

\section{Author affiliations}

${ }^{1}$ Applied Health Research Centre, Li ka Shing Knowledge Institute, St Michael's Hospital, Toronto, Ontario, Canada

${ }^{2}$ School of Kinesiology and Health Science, York University, Toronto, Ontario, Canada ${ }^{3}$ Division of Endocrinology, Women's College Hospital, Toronto, Ontario, Canada ${ }^{4}$ WCH Institute for Health System Solutions and Virtual Care, Toronto, Ontario, Canada

${ }^{5}$ Keenan Research Centre for Biomedical Science and Li Ka Shing Knowledge Institute, St Michael's Hospital, Toronto, Ontario, Canada

${ }^{6}$ Department of Physical Therapy and Rehabilitation Sciences Institute, University of Toronto, Toronto, Ontario, Canada

Acknowledgements The authors thank the staff and patients of the Young Adult Diabetes Clinics of St Michael's Hospital and Women's College Hospital, as well as the staff at Diabetes Canada.

Contributors All authors contributed to the conception and design of the study. CP contributed substantially to the collection, interpretation and analysis of the data, as well as taking primary responsibility for drafting the manuscript. BM provided administrative, technical, and material support, contributed to the analysis and interpretation of the data, and assisted in drafting the manuscript. GM provided administrative support and assisted in drafting the manuscript. JAP and AA contributed to data interpretation and drafting of the manuscript. All authors read and approved the final version of the manuscript.

Funding This study received funding support from the Alternative Funding Plan Innovation Funds from the Ontario Ministry of Health and Long-Term Care, the RDV Foundation, and Translational Innovation Funds from St Michael's Hospital Foundation. BM was supported by a Queen Elizabeth II Graduate Scholarship in Science and Technology. AA is supported by a Diabetes Investigator Award from Diabetes Canada and is the Keenan Chair in Medicine at St Michael's Hospital and University of Toronto.

Competing interests $\mathrm{CP}$ has received research funding through her institution from Takeda Canada. JAP has received research funding through her institution from Medtronic through the MaRS EXCITE program, as well as Janssen. AA has received research support through his institution from AstraZeneca and Boehringer Ingelheim, is listed as an inventor on an unrelated patent with Boehringer Ingelheim, has received an unrestricted educational grant from Eli Lilly, and has received honoraria from Novo Nordisk, Eli Lilly, Boehringer Ingelheim, Abbott and Dexcom.

\section{Patient consent for publication Not required.}

Ethics approval Ethical approval for the study was provided by the research ethics boards of St Michael's Hospital (REB\# 16-227) and Women's College Hospital (REB\# 2016-0089-E).

Provenance and peer review Not commissioned; externally peer reviewed.

Data availability statement Data are available upon reasonable request. The data sets generated during the current study are not publicly available due to the highly sensitive nature of the research but are available from the corresponding author on reasonable request. Due to the sensitive nature of these data and the need to ensure confidentiality, all identifiers from the data set will be removed prior to the data set being made available to interested researchers. This practice is in accordance with the Canadian Institutes of Health Research's (CIHR) policy statements on best practices for protecting privacy in health research.

Open access This is an open access article distributed in accordance with the Creative Commons Attribution Non Commercial (CC BY-NC 4.0) license, which permits others to distribute, remix, adapt, build upon this work non-commercially, and license their derivative works on different terms, provided the original work is properly cited, appropriate credit is given, any changes made indicated, and the use is non-commercial. See: http://creativecommons.org/licenses/by-nc/4.0/.

\section{ORCID ID}

Cheryl Pritlove http://orcid.org/0000-0001-9627-7562

\section{REFERENCES}

1 Hanna KM, Weaver MT, Slaven JE, et al. Diabetes-Related quality of life and the demands and burdens of diabetes care among emerging adults with type 1 diabetes in the year after high school graduation. Res Nurs Health 2014;37:399-408.

2 Sparud-Lundin C, Ohrn I, Danielson E. Redefining relationships and identity in young adults with type 1 diabetes. $J$ Adv Nurs 2010;66:128-38.

3 Marshall M, Carter B, Rose K. Adolescents living with diabetes: selfcare and parental relationships. J Diabetes Nurs 2006;10:8-13.

4 Hilliard ME, Perlus JG, Clark LM, et al. Perspectives from before and after the pediatric to adult care transition: a mixed-methods study in type 1 diabetes. Diabetes Care 2014;37:346-54.

5 Kyngäs $\mathrm{H}$, Hentinen M, Barlow JH. Adolescents' perceptions of physicians, nurses, parents and friends: help or hindrance in compliance with diabetes self-care? J Adv Nurs 1998;27:760-9.

6 Mellin AE, Neumark-Sztainer D, Patterson JM. Parenting adolescent girls with type 1 diabetes: parents' perspectives. J Pediatr Psychol 2004;29:221-30.

7 Heath G, Farre A, Shaw K. Parenting a child with chronic illness as they transition into adulthood: a systematic review and thematic synthesis of parents' experiences. Patient Educ Couns 2017;100:76-92.

8 Arnett JJ. Emerging adulthood. A theory of development from the late teens through the twenties. Am Psychol 2000;55:469-80.

9 Monaghan M, Helgeson V, Wiebe D. Type 1 diabetes in young adulthood. Curr Diabetes Rev 2015;11:239-50.

10 McCarthy MM, Grey M. Type 1 diabetes self-management from emerging adulthood through older adulthood. Diabetes Care 2018;41:1608-14. 
11 Ritholz MD, Wolpert H, Beste M, et al. Patient-Provider relationships across the transition from pediatric to adult diabetes care: a qualitative study. Diabetes Educ 2014;40:40-7.

12 Peters A, Laffel L, American Diabetes Association Transitions Working Group. Diabetes care for emerging adults: recommendations for transition from pediatric to adult diabetes care systems: a position statement of the American diabetes association, with representation by the American College of osteopathic family physicians, the American Academy of pediatrics, the American association of clinical endocrinologists, the American osteopathic association, the centers for disease control and prevention, children with diabetes, the endocrine Society, the International Society for pediatric and adolescent diabetes, juvenile diabetes research Foundation international, the National diabetes education program, and the pediatric endocrine Society (formerly Lawson Wilkins pediatric endocrine Society). Diabetes Care 2011;34:2477-85.

13 Lindström C, Åman J, Norberg AL, et al. "Mission Impossible"; the Mothering of a Child With Type 1 Diabetes - From the Perspective of Mothers Experiencing Burnout. J Pediatr Nurs 2017;36:149-56.

14 Ersig AL, Tsalikian E, Coffey J, et al. Stressors in teens with type 1 diabetes and their parents: immediate and long-term implications for transition to self-management. J Pediatr Nurs 2016;31:390-6.

15 Quirk H, Blake H, Dee B, et al. "You can't just jump on a bike and go": a qualitative study exploring parents' perceptions of physical activity in children with type 1 diabetes. BMC Pediatr 2014;14:313

16 Whittemore R, Jaser S, Chao A, et al. Psychological experience of parents of children with type 1 diabetes: a systematic mixed-studies review. Diabetes Educ 2012;38:562-79.

17 Marshall M, Carter B, Rose K, et al. Living with type 1 diabetes: perceptions of children and their parents. J Clin Nurs 2009;18:1703-10.

18 Ridge K, Thomas S, Jackson P, et al. Diabetes-oriented learning family intervention (DOLFIN): a feasibility study evaluating an intervention for carers of young persons with type 1 diabetes. Diabet Med 2014;31:55-60.

19 Nordfeldt S, Ängarne-Lindberg T, Nordwall M, et al. Parents of adolescents with type 1 diabetes--their views on information and communication needs and internet use. A qualitative study. PLoS One 2013;8:e62096.

20 Markowitz B, Parsons JA, Advani A. Diabetes in emerging adulthood: transitions lost in translation. Can J Diabetes 2017;41:1-5.

21 Helgeson VS, Reynolds KA, Snyder PR, et al. Characterizing the transition from paediatric to adult care among emerging adults with type 1 diabetes. Diabet Med 2013;30:610-5.

22 Creswell JW. Qualitative inquiry and research design choosing among five traditions. Thousand Oaks, CA: Sage Publications, 1998.
23 Luborsky MR, Rubinstein RL. Sampling in qualitative research: rationale, issues, and methods. Res Aging 1995;17:89-113.

24 Richards L. Handling qualitative data : a practical guide. London: SAGE, 2005.

25 MacQueen KM, McLellan E, Kay K, et al. Codebook development for team-based qualitative analysis. CAM Journal 1998;10:31-6.

26 Boeije $\mathrm{H}$. A purposeful approach to the constant comparative method in the analysis of qualitative interviews. Qual Quant 2002;36:391-409.

27 Tracy SJ. Qualitative Quality: Eight "Big-Tent" Criteria for Excellent Qualitative Research. Qual Inq 2010;16:837-51.

28 Saunders B, Sim J, Kingstone T, et al. Saturation in qualitative research: exploring its conceptualization and operationalization. Qual Quant 2018;52:1893-907.

29 Kuzel AJ. Sampling in qualitative inquiry. In: Crabtree BF, Miller WL, eds. Doing qualitative research. Newbury Park, CA: Sage, 1992: 31-44.

30 Green J, Thorogood N. Qualitative methods in health services research. 3rd Ed. Los Angeles: Sage, 2014.

31 Allen D, Channon S, Lowes L, et al. Behind the scenes: the changing roles of parents in the transition from child to adult diabetes service. Diabet Med 2011;28:994-1000.

32 Ness MM, Saylor J, Selekman J. Maternal experiences of transitioning their emerging adult with type 1 diabetes to College. Diabetes Educ 2018;44:178-87.

33 Fegran L, Hall EOC, Uhrenfeldt L, et al. Adolescents' and young adults' transition experiences when transferring from paediatric to adult care: a qualitative metasynthesis. Int J Nurs Stud 2014:51:123-35.

34 Vloemans AF, Eilander MMA, Rotteveel J, et al. Youth with type 1 diabetes taking responsibility for self-management: the importance of executive functioning in achieving glycemic control: results from the longitudinal DINO study. Diabetes Care 2019;42:225-31.

35 Stibbe A. Health and the Social Construction of Masculinity in Men's Health Magazine. Men Masc 2004;7:31-51.

36 Gillani SW, Ansari IA, Zaghloul HA, et al. Women with type 1 diabetes mellitus: effect of disease and Psychosocial-Related correlates on health-related quality of life. J Diabetes Res 2018;2018:1-10.

37 Maiorino MI, Bellastella G, Casciano O, et al. Gender-differences in glycemic control and diabetes related factors in young adults with type 1 diabetes: results from the Metro study. Endocrine 2018;61:240-7.

38 Luxton M. Feminist political economy in Canada and the politics of social. In: Bezanson K, Luxton M, eds. Social Reproduction: Feminist Political Economy Challenges Neo-Liberalism Montreal \& Kingston: McGill-Queen's University Press, 2006. 